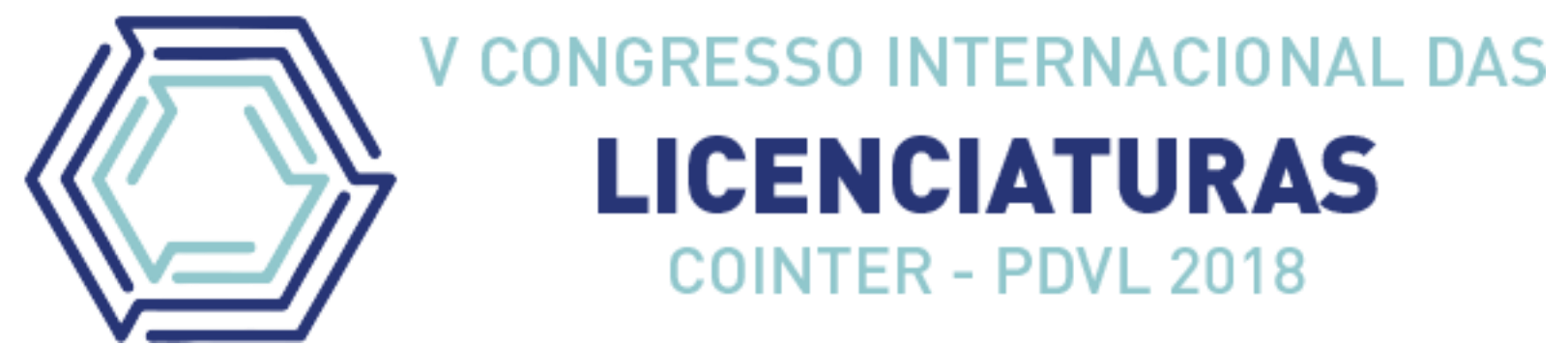

\title{
VOCAÇÃO DOCENTE DE LICENCIANDOS DO INSTITUTO FEDERAL DO PIAUII, CAMPUS TERESINA CENTRAL
}

\author{
TEACHING VOCATION OF LICENSORS OF THE FEDERAL INSTITUTE OF \\ PIAUÍ, CAMPUS TERESINA CENTRAL
}

\author{
Apresentação: Comunicação Oral \\ Vanessa Cardoso Pereira ${ }^{1}$; Marlúcia da Silva Bezerra Lacerda ${ }^{2}$
}

DOI: https://doi.org/10.31692/2358-9728.VCOINTERPDVL.2018.00164

\begin{abstract}
Resumo
A licenciatura possui a missão de formar docentes, com a capacidade de ensinar e repassar o conhecimento, que é adquirido na academia, pois o conhecimento é uma das ferramentas primordiais no ensino aprendizagem, e que tal utilitário necessita de um auxiliador com múltiplas habilidades. Nestes cursos, as disciplinas da área pedagógica têm o papel importante de preparar os acadêmicos para a realidade da sala de aula conduzindo estes para a melhor forma de transpor os conhecimentos específicos da área escolhida, formando uma rede interdisciplinar que propicia uma noção discente do que é o "ser docente". Nos cursos de licenciatura do Instituto Federal do Piauí, Campus Teresina Central. Os licenciandos se identificam de fato com a docência? Este estudo teve como processo metodológico a aplicação de questionários, contendo dez questões de múltipla escolha, na qual buscam os fatores dos estudantes antes de ingressar no curso, no atual momento e após a formação. Entre os 100 alunos das licenciaturas do IFPI/CTC pesquisados $45 \%$ pertenciam ao curso de licenciatura em Ciências Biológicas, $19 \%$ ao de química, $20 \%$ de Matemática e $16 \%$ ao curso de Física. Os resultados demonstraram que os estudantes se identificam a licenciatura e possuem apoio familiar para seguirem a carreira, entretanto há uma insatisfação quanto a carga horária das disciplinas específicas. É observado também um tangenciamento da educação básica, mediante por motivo de uma desvalorização financeira e social. Tais dados promoveram uma reflexão sobre o perfil vocacional dos estudantes de licenciatura do Instituto federal do Piauí, e apontam que o estudante possui tal perfil, ainda que algumas dúvidas em relação ao futuro da carreira.
\end{abstract}

Palavras-Chave: licenciatura, pedagógicas, discentes, evasão.

\footnotetext{
${ }^{1}$ Licencianda em Ciências Biológicas, Instituto Federal do Piauí- Campus Teresina Central, E-mail: vanessaa.card@gmail.com

${ }^{2}$ Professora do Curso de Lic. Em Ciências Biológicas, Doutorado em Ciência Animal, Instituto Federal do Piauí, Email: marlucia.lacerda@ifpi.edu.br
} 


\begin{abstract}
The degree has the ability to train teachers, with the ability to teach and pass on the knowledge, which is acquired in the academy, because knowledge is one of the primordial tools in teaching learning, and that such a utility needs a helper with multiple skills. In these courses, the pedagogical disciplines have the important role of preparing the students for the reality of the classroom, leading them to the best way of transposing the specific knowledge of the chosen area, forming an interdisciplinary network that provides a student notion of what it is the "being a teacher". In the undergraduate courses of the Federal Institute of Piauí, Campus Teresina Central do the students actually identify themselves with teaching? This study had as methodological process the application of questionnaires, containing ten questions of multiple choice, in which they search the factors of the students before entering the course, at the present moment and after the formation. Among the 100 undergraduate students of the IFPI / CTC surveyed, $45 \%$ belonged to the licentiate course in Biological Sciences, $19 \%$ to chemistry, $20 \%$ to Mathematics and $16 \%$ to Physics. The results showed that the students identify the degree and have family support to follow the career, however there is a dissatisfaction as to the timetable of the specific disciplines. It is also observed a tangency of basic education, due to a financial and social devaluation. These data promoted a reflection on the vocational profile of the undergraduate students of the Federal Institute of Piauí, and indicate that the student has such a profile, although some doubts about the future of the career.
\end{abstract}

Keywords: undergraduate, pedagogic, students, evasion.

\title{
Introdução
}

Os cursos de licenciatura possuem a missão de formar novos professores, aliando as disciplinas específicas com as disciplinas pedagógicas, de modo a conduzir os licenciandos para o pleno exercício docente, pois o domínio do conteúdo específico da área é validado pela capacidade de repassar o conhecimento. Para tanto, a formação do professor abrange duas dimensões: a formação teórico-científica, que inclui a formação acadêmica específica na disciplina em que o docente vai especializar-se e a formação pedagógica, que envolve os conhecimentos da filosofia, sociologia, história da educação e da própria pedagogia que contribuem para o esclarecimento do fenômeno educativo no contexto histórico social; a formação técnico-prática visando a preparação profissional específica para a docência incluindo a didática, as metodologias específicas da matéria, a psicologia da Educação, a pesquisa educacional e outras (LIBÂNEO, 1999)

Contudo, mesmo sendo uma profissão de formação complexa, visando agregar 
conhecimentos práticos e teóricos, a docência é desvalorizada pela sociedade brasileira, enquanto muitas nações desenvolvidas crescem e se desenvolvem tendo como sua base a educação de qualidade. Pois reconhecem que tal educação só é plena quando o devido respeito e valorização do professor for alcançado, seja financeiramente, como pela sua importância na sociedade. E essa desvalorização recorrente no Brasil, afeta também muitas vezes a escolha dos estudantes na opção de curso de ensino superior, no momento de escolher a carreira de licenciatura, resultando em cursos com pouca seletividade e evasão após o início do curso.

Índices de evasão são observados no decorrer do período de formação dos cursos de licenciatura ofertados pelo Instituto Federal do Piauí, Campus Teresina Central - IFPI/CTC, onde há tangenciamento para outras carreiras. Tartuce et al. (2010), falam que a diminuição da procura, por parte dos jovens, da profissão de professor tem-se tornado objeto de preocupação nos últimos anos. Estes autores enfatizam ainda que a falta de docentes bem formados e a escassez de profissionais para algumas áreas disciplinares dos últimos anos do ensino fundamental e ensino médio é discutida tanto em artigos acadêmicos como na mídia. Ao mesmo tempo, divulga-se não só a tendência de queda na demanda pelas licenciaturas e no número de formandos, mas também a mudança de perfil do público que busca a docência TARTUCE et al., 2010).

Diante do exposto, neste trabalho busca-se investigar as possíveis causas que deixam os estudantes das licenciaturas do Instituto Federal do Piauí/Campus Teresina Central desestimulados como o curso, construindo o perfil vocacional desses estudantes. Pretende-se através dessa construção, averiguar possíveis fatores que possam estar desmotivando estes discentes.

\section{Fundamentação Teórica}

Parece-nos importante que o fenômeno de evasão universitária deva ser compreendido enquanto centrado na escolha profissional dos jovens, envolvido nas possibilidades de um projeto pessoal de vida. Se há evasão, existem também os alunos que permanecem insatisfeitos no curso e, uma vez diplomados, sentem-se desajustados na atividade profissional. Alinhamento profissional dos que saem, dos que ficam e dos que se formam. Se considerarmos todos estes casos como diferentes modos de afastamento e desligamento, os números de evasão universitária crescem enormemente. (PAIDEIA, 1993)

Segundo Gomes e Malacarne (2008) o aluno sendo ainda imaturo, em muitos casos, para decidir seu futuro profissional, percebe-se, pela prática, que muitos mudam a caminhada 
universitária ao perceber, durante o curso, que a opção escolhida nada tinha a ver com suas expectativas. Daí a importância de uma avaliação séria que indique pontos fortes e fracos dos alunos, uma avaliação que não seja estereotipada e sim que leve em conta todas as habilidades dos alunos.

O perfil do professor universitário não deve se restringir a apenas deter conhecimentos técnicos referentes à sua disciplina, pois ele, a todo momento, é tido como referencial de conduta para os seus discípulos. Portanto, é de fundamental importância que o docente se perceba como agente transformador, para poder, de forma consciente, intervir na formação dos alunos sob sua responsabilidade. É preocupante vermos alguns professores universitários com um discurso para a sala de aula e outro para a sua vida extraclasse. Essa postura contraditória desnorteia os alunos e sendo eles o futuro fundamento da sociedade, está se vê, repetidamente, sem a claridade fornecida pelos firmes princípios éticos de conduta (ROCHA e CORREIA, 2006).

Muitos fatores influenciam na escolha de uma profissão, de características individuais a convicções políticas e religiosas, valores e crenças, situação político-econômica do país, a família (SANTOS, 2005). Este autor aponta a família como um dos principais fatores que pode ajudar ou dificultar no momento da escolha e na decisão do jovem como um dos elementos de transformação da própria família.

Existem uma série de fatores que interferem no poder de decisão do discente em relação a permanência em cursos de licenciatura, são eles: nível de conhecimento que tornam possível a entrada no curso; motivação para realizar atividades acadêmicas; realização pessoal; indicação por outras pessoas graduadas; infraestrutura das instituições; disponibilidade, devido a conciliação com o trabalho; desvalorização da profissão pela sociedade (ARRIGO, CROVE e BROIETTI, 2017).

\section{Metodologia}

Esta pesquisa foi realizada no período letivo de 2018.1 com estudantes de licenciatura do Instituto Federal do Piauí (IFPI), Campus Teresina Central (CTC). Participaram como voluntários discentes regularmente matriculados nos $2^{\circ}$ e $8^{\circ}$ módulos dos cursos de licenciatura do Departamento de Formação de Professores: Ciências Biológicas, Química, Física e Matemática.

Foram aplicados questionários que abordaram 10 questões (Quadro 1), dentre elas; os motivos que possam ter desestimulado os alunos durante o curso, a opinião familiar sobre o 
curso, as primeiras experiências em sala de aula e as perspectivas após o término do curso.

O presente trabalho foi desenvolvido dentro da abordagem quantitativa e qualitativa de pesquisa em educação na formação de professores, com produção de resultados através da análise de 100 questionários aplicados contendo alternativas de múltipla escolha.

Quadro 1. Questões aplicadas aos licenciandos do Instituto Federal do Piauí, Campus

Teresina Central participantes da pesquisa.

\section{$\mathbf{N}^{0}$ questões-Especificação}

Q01-Licenciatura em:

Q02-Período/módulo:

Q03-Durante seu ensino médio, como era seu rendimento escolar, em relação às notas

Q04-O que lhe desestimulou em algum momento do curso?

Q05-O que deixaria o curso mais interessante?

Q06-Por que ingressou no curso de licenciatura?

Q07-Quais as primeiras impressões com a experiência em sala de aula?Pibid/estágio/RP, etc.

Q08-Sua família gosta, lhe incentiva no curso?

Q09- Na sua opinião o que pode desestimular o ingresso do estudante na licenciatura

Q10-Como pretende continuar a carreira

\section{Resultados e Discussões}

Entre os 100 alunos das licenciaturas do IFPI/CTC pesquisados $45 \%$ pertenciam ao curso de licenciatura em Ciências Biológicas, 19\% ao de química, 20\% de Matemática e 16\% ao curso de Física.

Quando foram questionados sobre o rendimento escolar no ensino médio, 67\% relataram possuir notas com médias superiores a 8,0 e apenas $2 \%$ dos alunos revelaram ter média de notas inferiores a 7,0. Esses dados apontam que os alunos da licenciatura possuíam boas notas no ensino médio.

Em relação a Q04 que discute o que desestimulou os estudantes de licenciatura em algum momento do curso, apenas 9,8\% relataram estar satisfeitos com o curso. O índice com grande representatividade, $48 \%$ dos estudantes, afirmaram que o desestímulo está ligado à conduta de algum professor, o que demonstra que os professores influenciam diretamente na vida acadêmica do estudante e que comportamentos éticos e morais devem estar entre as premissas do "professor que forma professor" (Figura 1).

Figura 1. Resposta dos licenciandos pesquisados quando questionados sobre o que mais o desestimulou em algum momento do curso. 


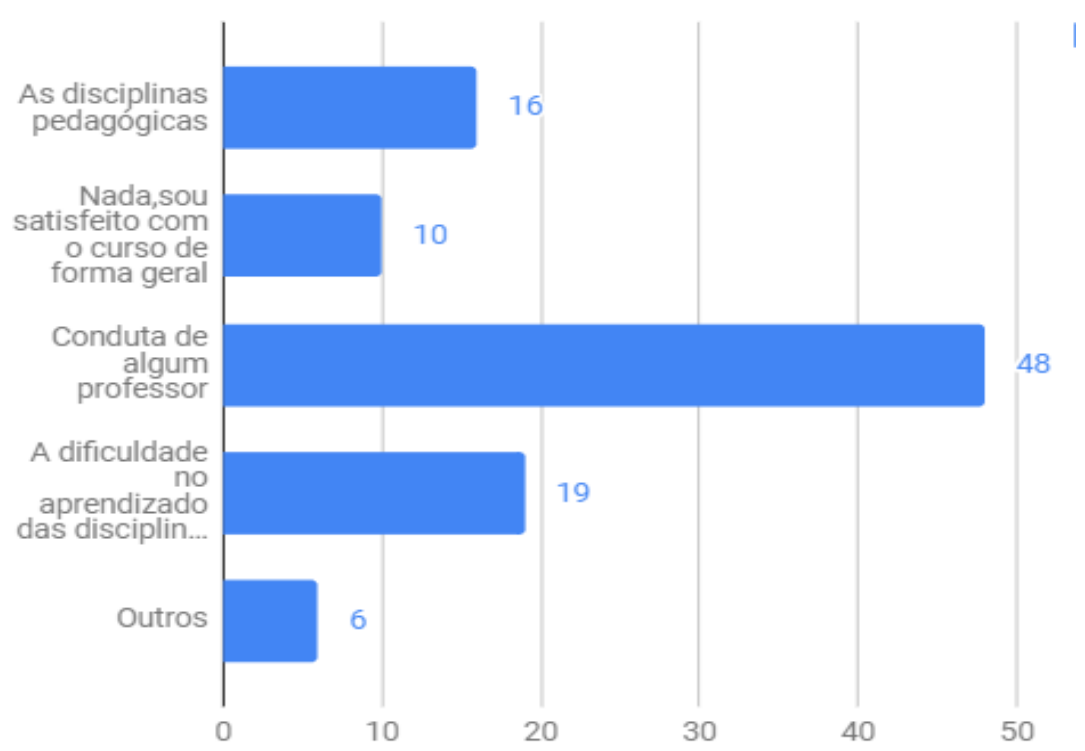

Fonte: Dos próprios autores.

Questionados sobre que aspectos poderiam deixar o curso mais interessante (Q05), a predominância foi a inserção de mais aulas práticas, de laboratório ou em campo, que teve $54,9 \%$ apontados pelos futuros docentes, o aumento da carga horária das disciplinas e inclusão de mais disciplinas específicas obtiveram $32 \%$ e $23 \%$, respectivamente. Nota-se que os licenciandos apontam para um perfil com maior afinidade pelas disciplinas específicas em detrimento das pedagógicas, observando assim uma tendência para o bacharel e não para a docência. Outra vertente seria a análise de que a instituição carece de ofertas de atividades práticas experimentais, sendo o déficit neste aspecto um fator a corroborar de maneira expressiva para a formação docente nos cursos pesquisados.

Em relação aos motivos de terem ingressado em curso de licenciatura, 40,6\% afirmaram ser devido sua afinidade com as matérias no ensino médio, 29,7\% afirmaram que sempre tiveram vontade de ser professor, $21,8 \%$ não tinham certeza ao ingressar no curso, mas atualmente se encontram na licenciatura, 5,9\% precisavam fazer algum curso devido a pressão da sociedade, e $2 \%$ não possuem certeza se terminaram o curso.

A formação profissional do professor é um processo pedagógico, intencional e organizado (Libâneo, 1999). Ou seja, o aluno tem que se projetar na profissão desde o princípio, pesquisar sobre área de atuação e desafios. Sabemos que apenas afinidade com a matéria não é suficiente para que o aluno permaneça no curso, pois as disciplinas pedagógicas poderão ser motivo de desestímulo para aqueles que buscam se aprofundar apenas nas disciplinas específicas. Portanto, faz-se necessário uma identificação vocacional com as áreas teórico- 
práticas da profissão. Tais dados corroboram com as ideias de que muitos estudantes entram no curso, sem a certeza da carreira que pretendem seguir. Para Santos, (2004) as crises vivenciadas pelo adolescente e sua família incluem oscilações em sua definição profissional, e indagações quanto à escolha de uma profissão rentável e segura, mas que não satisfaz, ou a opção por uma atividade que atrai, mas que não traz estabilidade financeira.

O estágio é primeiro contato com a sala de aula, e com a realidade que irá fazer parte da vida dos futuros professores. Neste sentido, quando perguntados sobre quais foram primeiras impressões em sala de aula nos projetos de Pibid, residência pedagógica e na disciplina de estágio entre outras experiências em sala de aula, $40,2 \%$ se sentiram empolgados para ministrar as aulas. É possível analisar positivamente as experiências dos discentes, visto que esse item teve percentual expressivo. Outros 37,5\% relataram ficar assustados diante da realidade da sala de aula, 13,7\% ainda não vivenciaram essa experiência, devido estarem nos períodos iniciais, $4,9 \%$ pensaram em desistir do curso.

Experiências como essas podem ser um fator decisivo para desistência dos cursos de licenciatura, os discentes ao serem confrontados com a realidade das escolas públicas, com professores cansados da rotina, que muitas vezes aconselham ao estagiário que desistam da profissão e com alunos indisciplinados. Frente a todos esses fatores negativos, faz-se necessário que o licenciando esteja seguro da sua decisão pela docência (Figura 2).

Figura 2. Resposta dos licenciandos pesquisados quando questionados sobre quais as primeiras impressões com a experiência em sala de aula

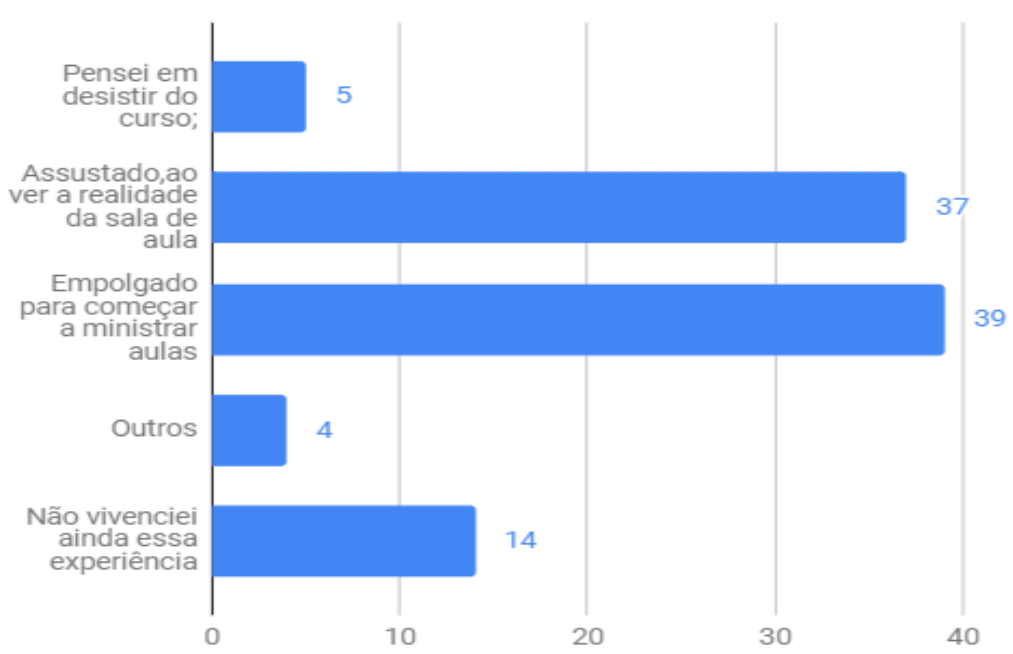

Fonte: Dos próprios autores.

Para Santos (2005) a família é um dos principais fatores que ajudam ou que dificultam 
no momento da escolha da carreira. Quando perguntados se a família apoiava e incentivava no curso, $82,4 \%$ disseram que sim e que sua família sente orgulho da escolha que eles tomaram, apenas $5,9 \%$, disseram que a família desvaloriza e não incentiva no curso.

Muitas vezes os pais acreditam que o melhor para seu filho, é estudar em cursos e grande prestígio social e com alta seletividade, havendo uma negatividade frente a escolhas na carreira de professor. Entretanto, esses dados mostram que mais da metade dos estudantes tem sim, o apoio da família. Apontado como aspecto positivo e não esperado para essa os resultados dessa pesquisa. (Figura 03)

Figura 3. Resposta dos licenciandos pesquisados quando questionados sobre o apoio familiar, diante do curso de licenciatura

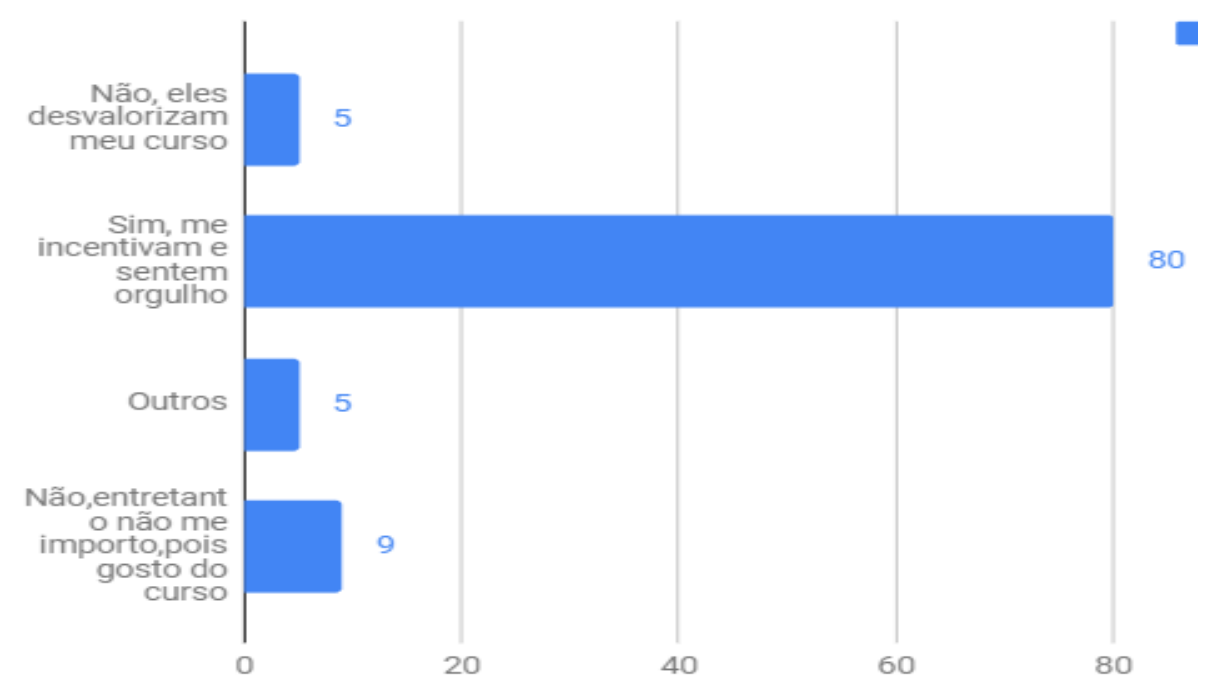

Fonte: Dos próprios autores.

Questionados sobre o que poderia desestimular o ingresso do estudante na licenciatura, a falta de reconhecimento da sociedade teve maior percentual com $36,6 \%$, a falta de respeito em sala de aula por parte dos alunos $29,3 \%$, desvalorização financeira $28,7 \%$, apenas $4,3 \%$, não se sentem desestimulado apenas 4,3\%. Segundo Pinto (2012) os valores iniciais e finais da carreira, de maneira geral, são muito baixos. O Brasil, em particular, se destaca pelo baixo valor do limite inferior, que só fica acima de Bolívia, Equador, Peru e Venezuela. Cabe ressaltar que o salário inicial é uma variável fundamental no momento de escolha de uma carreira. Essa desvalorização financeira e social e as dificuldades da educação nas escolas públicas brasileiras, afastam os estudantes. Este resultado mostra que este fator pode conduzir os licenciandos do IFPI/CTC a procurarem as profissões de grande prestígio na sociedade, provocando 
estreitamento na seletividade e qualidade dos estudantes que optam pela área da docência na instituição.

Reflexões como essas podem ser muito mais complexas e de âmbito sociológico, pois o não comprometimento de profissionais medianos, cria um ciclo de alunos com uma educação mediana, no qual os professores mais qualificados e capacitados, ocupam as vagas de escolas particulares ou de grande prestígio e os demais, ocupam as escolas públicas, delimitando as barreiras de uma "educação de qualidade" para aqueles que podem pagar, e para aqueles que não podem.

Segundo os dados levantados na questão de como irão proceder após o término do curso, $48 \%$ dos estudantes de licenciatura relataram que irão fazer mestrado para posteriormente ministrar aulas no ensino superior (Figura 4). Destacam-se ainda percentuais que apontaram a escolha de fazer outro curso superior e prestar concurso para outras áreas fora da licenciatura, apenas $20 \%$ afirmaram continuar a carreira de professor da educação básica.

Figura 4. Resposta dos licenciandos pesquisados quando questionados sobre o que esperam do futuro da carreira docente

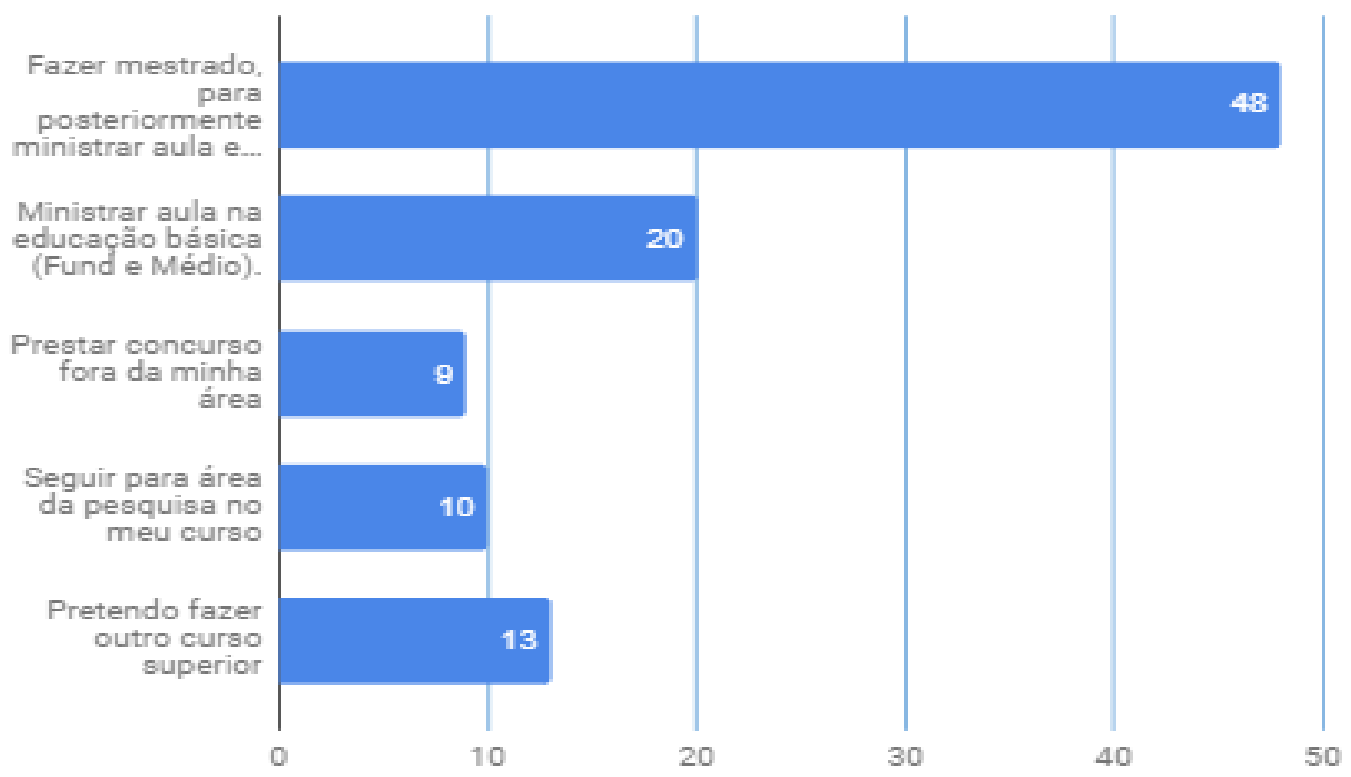

Fonte: Dos próprios autores.

Logo, os dados ratificam que muitos estudantes das licenciaturas do IFPI/CTE não desejam ser professores no ensino fundamental e médio, devido aos baixos salários e a 
indisciplina dos alunos, fatores elencados na Q09, pois corroboram com os resultados da Q10 que demonstram esse distanciamento da educação básica. Para Paideia (1993) se há evasão, existem também os alunos que permanecem insatisfeitos no curso e, uma vez diplomados, sentem-se desajustados na atividade profissional.

\section{CONCLUSÃO}

Sendo assim, podemos concluir que os alunos do Instituto Federal do Piauí, Campus Teresina Central, majoritariamente possuem perfil vocacional para licenciatura, e contam com o apoio familiar para seguirem a carreira. Entretanto, a instituição precisa avançar em relação às propostas curriculares associadas às disciplinas específicas, especialmente em relação à carga horária que é proposta na grade curricular. Promover a otimização de atividades práticas se caracteriza como um ponto forte para a melhoria do perfil vocacional docente dos licenciandos dos cursos de Química, Física, Matemática e Ciências Biológicas do Instituto federal do Piauí, Campus Teresina Central.

Apesar do empenho e vocação para o magistério, os estudantes também se sentem retraídos em relação a atuação na educação básica, creditando isto à desvalorização do professor pela sociedade e aos baixos salários. Há um tangenciamento dos estudantes para outras áreas do mercado de trabalho, para outros cursos superiores, para concursos fora da área da educação, bem como ainda preferência em ministrar aulas na educação superior.

\section{Referências}


ANDERSON, E. C. Influência das forças na persistência do estudante e realização. San Francisco-London: Jossey-BessPublishers, 1987.

ARRIGO, V; DE SOUZA, M. C. C.; BROIETTI, F. C. D.. Elementos caracterizadores de ingresso e evasão em um curso de licenciatura em química. ACTIO: Docência em Ciências, v. 2, n. 1, p. 243-262, 2017.

BARDAGI, M. P. Evasão e comportamento vocacional de universitários: estudos sobre o desenvolvimento de carreira na graduação. Tese de doutorado não publicada, Universidade Federal do Rio Grande do Sul, Porto Alegre, Rio Grande do Sul, 2007.

BUENO, J. L. O. A evasão de alunos. Paidéia, n. 5, p. 9-16, 1993.

DOS SANTOS, L. M. M. O papel da família e dos pares na escolha profissional. Psicologia em Estudo, v. 10, n. 1, p. 57-66, 2005.

GAIOSO, N. P. L. O fenômeno da evasão escolar na educação superior no Brasil. 2005. 75 f. Dissertação (Mestrado em Educação) - Programa de Pós-Graduação em Educação da Universidade Católica de Brasília, Brasília, 2005.

GOMES, A. R. C.; MALACARNE, V. Os alunos do ensino médio e os desafios das escolhas para a formação profissional. Material pedagógico. Disponível em: http://www.diaadiaeducacao.pr.gov.br/portals/pde/arquivos/2419-8.pdf. Acesso em 17 de out. 2018.

LIBÂNEO, J. C. Educação: pedagogia e didática-o campo investigativo da pedagogia e da didática no Brasil: esboço histórico e buscas de identidade epistemológica e profissional. Didática e formação de professores: percursos e perspectivas no Brasil e em Portugal. São Paulo: Cortez, p. 77-129, 1997.

LOUZANO, P. et al. Quem quer ser professor? Atratividade, seleção e formação do docente no Brasil. Estudos em avaliação educacional, v. 21, n. 47, p. 543-568, 2010.

PINTO, J. M. R. Remuneração adequada do professor: desafio à educação brasileira. Retratos da Escola, v. 3, n. 4, 2012.

ROCHA, C. B.; CORREIA, G. C. S. Ética na docência do ensino superior. Educare, v. 2, p. 1$8,2006$.

SANTANA, O. A. Teachers in Brazil: Social Mobility and Elements for Federalism Strategies. Creative Education, v. 06, p. 1629-1637, 2015.

TARTUCE, G. L. B. P.; NUNES, M. M. R.; DE ALMEIDA, P. C. A. Alunos do ensino médio e atratividade da carreira docente no Brasil. Cadernos de Pesquisa, v. 40, n. 140, p. 445-477, 2010 . 
